\title{
Square mesh panels in demersal trawls: does lateral positioning enhance fish contact probability?
}

\author{
Juan SAntos ${ }^{1, a}$, Bent HerrmanN ${ }^{2,3, b}$, Pascual Otero ${ }^{4}$, José FernandeZ ${ }^{5}$ and Nélida PÉreZ 6 \\ 1 Thünen-Institute of Baltic Sea Fisheries, Alter Hafen Süd 2, 18069 Rostock, Germany \\ 2 SINTEF Fisheries and Aquaculture, Fishing Gear Technology, Willemoesvej 2, 9850 Hirtshals, Denmark \\ 3 Norwegian College of Fishery and Aquatic Science, University of Troms $\varnothing, 9037$ Breivika, Troms $\emptyset$, Norway \\ 4 Tecnopesca PYM, S.L., C/ Rosalía de Castro 147, 36003 Pontevedra, Spain \\ 5 Cooperativa de Armadores de Pesca del Puerto de Vigo, Puerto Pesquero s/n, 36202 Vigo, Spain \\ ${ }^{6}$ Instituto Espanol de Oceanografía, C.O. Vigo, Subida a Radio Faro 50-52, 36390 Vigo, Spain
}

Received 6 January 2016; Accepted 30 June 2016

\begin{abstract}
Square mesh panels (SMPs) are often integrated into trawl sections ahead of diamond-mesh codends to improve release efficiency of undersized individuals of some species. Often, these release panels are integrated into the top panel of the trawl. This is particularly true for some mixed-trawl fisheries in western European Atlantic waters, where a diamond-mesh codend with a mesh size of only $70 \mathrm{~mm}$ can be applied, on the condition that an SMP with a mesh size of at least $100 \mathrm{~mm}$ is integrated into the upper panel of the trawl. The purpose of this SMP is to avoid catching undersized hake, for which the codend of $70 \mathrm{~mm}$ diamond mesh has been shown to have insufficient release potential. However, some studies have demonstrated this configuration to have poor release efficiency because most of the hake simply do not make contact with the SMP. Based on these poor results, we tested the release efficiency using $10 \mathrm{~m}$ long SMPs, integrated into the sides of the trawl in the last tapered section of the belly. The system is supplemented by a pentagon-shaped device, mounted in the belly to guide fish towards the SMPs. Based on the data collected we quantified the contact probability, i.e. the fraction of individuals that, during their travel towards the codend, came into contact with the SMPs to be size selected by them. Analysis revealed that $62 \%$ of hake (Merluccius merluccius), $44 \%$ of four-spotted megrim (Lepidorhombus boscii), 51\% of Norway lobster (Nephrops norvegicus), and $41 \%$ of blackmouth catshark (Galeus melastomus) made contact with the SMPs. Therefore, the contact probability estimated for side long escape panels (SLEP) by far exceeded that of SMPs integrated into the top of the gear. Based on these promising results, SLEP might be a potential tool for improving species and size selection also in other trawl fisheries where the traditional use of SMP's is not effective.
\end{abstract}

Keywords: Square mesh panels / Contact probability / Hake / Multispecies selectivity / Trawl

\section{Introduction}

Unselective fishing is the main cause for the high bycatch rates associated with demersal trawl fisheries (Kelleher 2005). Once on-board, these incidental catches are sorted and often thrown back to sea dead or dying. Discarding is a widespread fishing practice and one of the biggest issues in world fisheries (Catchpole et al. 2005; Kelleher 2005). Its occurrence is often associated with the prevalence of management regulations controlling what the fishermen land on harbour without influencing what they catch. Rather than incentivising selective fishing to avoid unintended catches, these management strategies encourage fishermen to discard those catches not allowed to land or with no commercial interest for them

\footnotetext{
${ }^{\text {a }}$ Corresponding author: juan.santos@thuenen.de

b Equal authorship
}

(Rochet and Trenkel 2005; Bellido et al. 2011). Discarding is widely seen as an unnecessary waste of natural resources that compromises the sustainability of fish stocks and fisheries (Hall et al. 2000). It decreases the efficiency of fishing operations and changes the trophic flows in foodwebs and entire ecosystems (Greenstreet et al. 1999; Catchpole et al. 2005). This perception has motivated regional or national political bodies to adopt concrete actions to reduce or completely avoid discards in commercial fisheries (Diamond and Beukers-Stewart 2011). The Landing Obligation (LO) for quoted species adopted by the European Common Fisheries Policy (CFP) reform (EU1380/2013) is the most recent milestone to shift the old paradigm in fisheries management; it seeks to prompt fishermen to find their own technical solutions towards more selective fishing, a stepping-point to progressively phase out discards in European fisheries. 
Altering codend selectivity has been one of the most used strategies to reduce the bycatch of undersized fish and thereby discarding in trawl fisheries. More recently, an increasing number of alternative selective devices have been developed to address specific bycatch problems (Glass 2000; Catchpole and Revill 2008). Square mesh panels (SMPs) are simple selective devices usually applied in demersal trawl fisheries when codend selectivity alone is not sufficient to prevent catches of unintended species or sizes (Catchpole and Revill 2008). The functioning of SMPs utilizes escape behaviour of bycatch species and facilitates escape by maintaining open mesh geometry in a certain area of the gear (Arkley 1990; Briggs 1992). The conceptual simplicity, and the effectiveness demonstrated for some gadoid species (Arkley 1990; Briggs 1992), have made SMPs one of the most tested and applied additional selection devices in Norway lobster fisheries in the past decades (ICES 2003; 2004). For SMPs to work efficiently in these fisheries, it is necessary that fish identify the potential escape zone (the section of the gear where the SMP is mounted), altering their swimming path towards the SMP to make contact with it. In this context, contact can be defined as the attempt made by the fish to use the selection device to escape (Sistiaga et al. 2010; Santos et al. 2015). Once such contact occurs, the size selection properties of the device will determine the possibilities of escapement for the fish. Several studies have investigated ways to improve SMP efficiency, by testing different panel dimensions (Armstrong et al. 1998; Graham and Kynoch 2001; Herrmann et al. 2015), different positions along the trawl (O'Neill et al. 2006; Herrmann et al. 2015), and the addition of multiple SMPs (Revill et al. 2007). In contrast to the variation in designs found in the literature, inserting SMPs in the upper panels of the trawl is a widespread strategy (Briggs 1992; Armstrong et al. 1998; Zuur et al. 2001; O’Neill et al. 2006; Frandsen et al. 2009). With this approach, it is assumed that fish will actively alter their swimming direction upwards to encounter the SMP, although the natural behaviour of many fish species is to stay clear of the netting around them (Glass 2000). On the other hand, it is reasonable to expect low contact probability for species swimming close to the bottom net panel, or for those species not perceiving the presence of the SMP in the travel towards the codend. Such behaviour can explain for example the poor release efficiency of this device observed in the Norway lobster fishery in the Bay of Biscay (Nikolic et al. 2015; Alzorriz et al. 2016), where fishermen are allowed to use diamond-mesh codends with a mesh size of $70 \mathrm{~mm}$, on the condition that an SMP with a mesh size of at least $100 \mathrm{~mm}$ is integrated into the upper panel. Using French onboard-observer data, Nikolic et al. (2015) have demonstrated that SMPs mounted in the top of the net ahead of the codend did not mitigate the fishery's bycatch problem, and the catch of small hake remains high. The findings of Nikolic et al. (2015) are consistent with recent sea trials carried out in an equivalent Basque trawl fishery, which estimated that only $\sim 4 \%$ of hake entering the gear make contact with the standard SMP (Alzorriz et al. 2016). This low contact probability indicates that hake does not use the escaping zone; therefore, it cannot be expected to reduce bycatch of undersized hake substantially by inserting an SMP on the top of the net.
Contrary to the widespread strategy for utilizing SMPs, this paper investigates an alternative selection system based on positioning two long SMPs (hereafter referred to as side long escape panels (SLEP)) into the lateral sides of the trawl belly. The new selection system includes a guiding device to enhance fish contact with the SLEP. Mounting selective devices in the sides of the gear has been demonstrated to be efficient in releasing small roundfish (Swedish codend) (Madsen 2007) or flatfish species (FRESWIND) (Santos et al. 2015). In the present study, the aim with this alternative positioning is to increase the probability that species such as hake are sizeselected by the SMP on their way to the codend. The SLEP was developed to reduce the high bycatch rates observed in the Northwest Iberian bottom otter trawl fishery (fleet segment SP_OTB_DEF_01). The concept relies on fishermen observations, who during their fishing activities often notice high concentrations of fish meshed in the lateral sides of the trawl belly, indicating that many fish contact the netting naturally at this area of the trawl. Unlike SMPs inserted in the top panel, the effectiveness of SLEP does not rely on changes in the individual's swimming direction in the presence of SMPs. Rather, it utilizes their natural swimming path towards the codend.

Fernandes et al. (2015) analyzed the discard composition of the Iberian bottom otter trawl fishery using data from the Spanish on-board sampling programme and found that the highest discards rates (more than $50 \%$ of total catch) occurred during trips targeting demersal species including anglerfish (Lophius spp.), hake, and four-spotted megrim (hereafter referred to as megrim). Specifically for the target species, the high annual discard rates estimated for hake (ranging from $\sim 14 \%$ to $\sim 40 \%$ of the total catch weight, between 2011 and 2013) and megrim (from $24 \%$ to $\sim 41 \%$ for the same period; ICES 2015). were of concern. It is mandatory for the target fleet segment to use diamond-mesh codends with a mesh size of at least $70 \mathrm{~mm}$ (Real Decreto1441/1999). However, the fleet's high discard volume estimated in recent years indicates that codend selectivity is not sufficient to reduce the bycatch in the fishery. This problem makes the fishery a perfect case study to test the SLEP.

The aim of this study is to assess the efficiency of SLEP to release fish from the gear before they enter the codend, and its potential application to reduce the bycatch in demersal mixed fisheries. Specifically, we are interested in assessing the advantages of inserting the SMPs in the lateral sides of the gear to achieve high probability of fish contact.

\section{Materials and methods}

\subsection{SLEP design and experimental gear}

The SLEP consisted of net pieces $10 \mathrm{~m}$ in length mounted on the lateral sides of the aft part of the belly section. Diamond polyethylene (PE) netting with $110 \mathrm{~mm}$ mesh size and $3 \mathrm{~mm}$ single twine was used, but was turned $45^{\circ}$ to force the mesh to assume a square shape during fishing. In addition, two net pieces forming a pentagon-shaped guiding device were inserted in the belly to further improve the probability that 


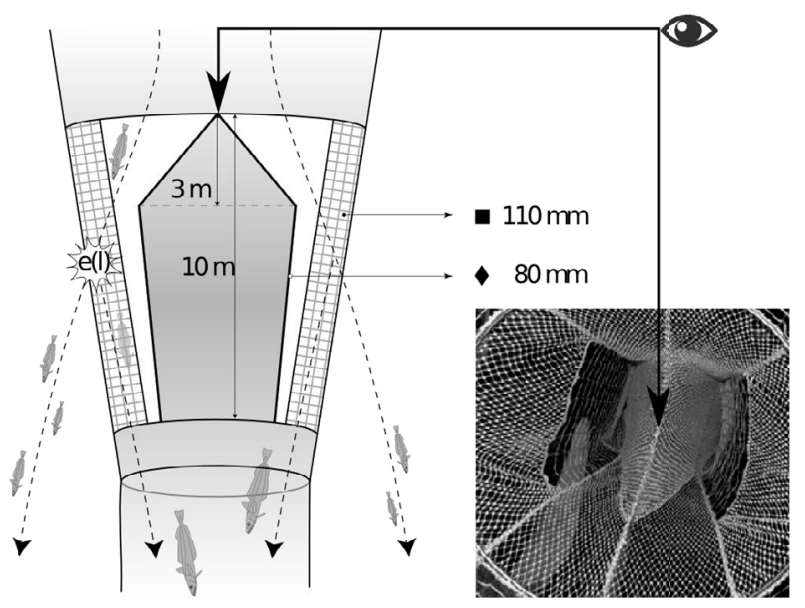

Fig. 1. Functioning scheme with constructive details of SLEP. The pentagon-shaped device is intended to guide fish towards the lateral sides of the belly, where the SMPs are mounted. After contacting the SMPs, the probability that a fish will escape is determined by the sizeselective properties of the open meshes. Bottom right: Front view of a scaled-up version of SLEP.

fish will contact the lateral SMPs. The pentagon-shaped guiding device was constructed using $80 \mathrm{~mm}$ mesh size $2.5 \mathrm{~mm}$ single-twine diamond netting, and the total length was $13 \mathrm{~m}$ (125 meshes). The vertex of the "V" was oriented towards the front of the gear and the endpoints towards the sides of the belly, to guide fish sideways towards the SLEP zone (Fig. 1). The strategy of mounting a guiding device in the central path of the cross section of the gear to encourage fish contact with the escape windows is analogous to the strategy applied in the FRESWIND concept, which also includes a deflector mounted in front of the escape zone (Santos et al. 2015).

SLEP and the pentagon-shaped guiding device were mounted in a standard four-panel gear introduced in the commercial fishery in recent decades. The vertical dimensions of SLEP were 20 meshes in the fore decreasing to 12 meshes in the aft, and were defined considering the height of the lateral sides of the gear where the panels were mounted ( $\sim 1 \mathrm{~m}$ and $0.6 \mathrm{~m}$, respectively), with the aim of keeping the turned meshes of the SLEP open during towing. The experimental gear was tested in commercial conditions using a fishing vessel from the northwest Iberian bottom otter trawl fleet. The trawl was rigged with TPC-5 model doors, weighing $850 \mathrm{~kg}$ and connected to the trawl by $260 \mathrm{~m}$ Polysteel sweeps and $15 \mathrm{~m}$ bridles. The footrope was made of steel wire covered with $80 \mathrm{~mm}$ diameter rubber discs, and the total length/weight was $80 \mathrm{~m} / 440 \mathrm{~kg}$. The codend was constructed using $75 \mathrm{~mm}$ nominal-sized diamond mesh, according to Spanish regulations (Real Decreto 1441/1999).

\subsection{Species investigated}

Four species were selected for the investigation from the list of species available in the catches: hake and megrim, two of the most important target species, which present high discard ratios in the fishery, Norway lobster, a valuable target species in Europe, but not considered a primary target species in the

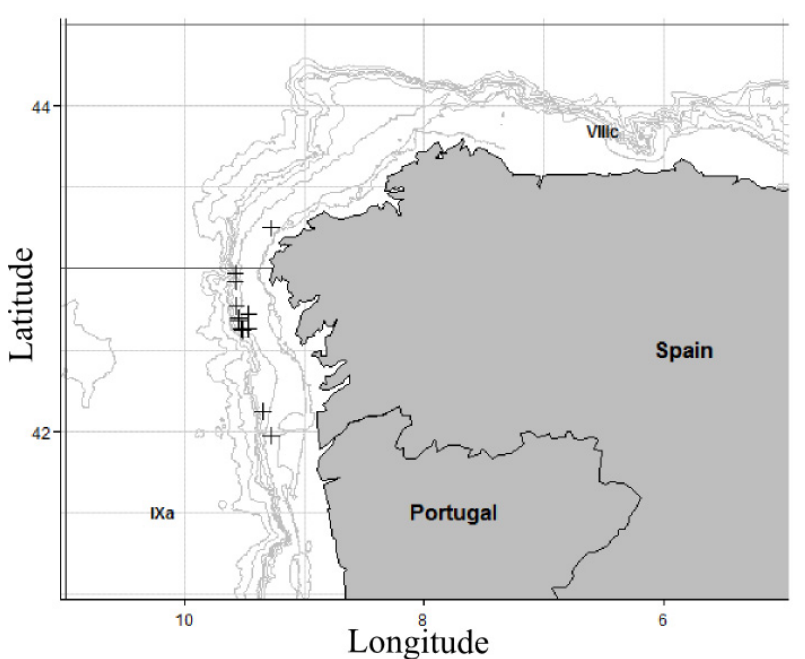

Fig. 2. Spatial distribution of the experimental hauls with the F/V Nuevo San Cibrán.

fishery investigated because of its scarcity on the local fishing grounds, and black-mouthed catshark (hereafter referred to as catshark), the bycatch species with the largest discard volume.

\subsection{Sea trials and data collection}

Sea trials were conducted using the commercial vessel "Nuevo San Cibrán", an otter trawler, with 490 HP and 27.9 m long, which is representative of the demersal mixed fishery in western Galician waters (ICES VIIIc-IXa; Fig. 2).

Two PE covers made of $40 \mathrm{~mm}$ diamond mesh were attached to the sides of the belly where the SLEP was inserted, and the catches obtained in both side covers were put in a single bin during the data collection (hereafter referred to as compartment P). A codend cover (CC) $17.5 \mathrm{~m}$ long of $40 \mathrm{~mm}$ diamond mesh was used to collect codend escapees (Fig. 3). Two hoops were mounted in the cover codend to prevent physical contact between the cover and the codend. Codend catches were separated into two compartments: the catch fraction retained on board for landing (R), and the discarded catch fraction (D). The design of the hoops with insufficient diameter (considering the recommendations stated in Wileman et al. 1996), and the small catches observed in the CC compartment, led to concern that the cover might have masked the codend meshes during the sea trials, affecting its selectivity. Therefore, catch information from the R, D, and CC compartments were treated as single compartments in subsequent analysis.

Catch sampling was carried out separately for each compartment. A total of 54 species or group of species, including fish and invertebrates, were observed in the catches. The large number of species observed forced subsampling over the different hauls. Target fish species were measured to the half centimetre below (total length), while Norway lobster were measured to the millimetre below (cephalothorax length). 


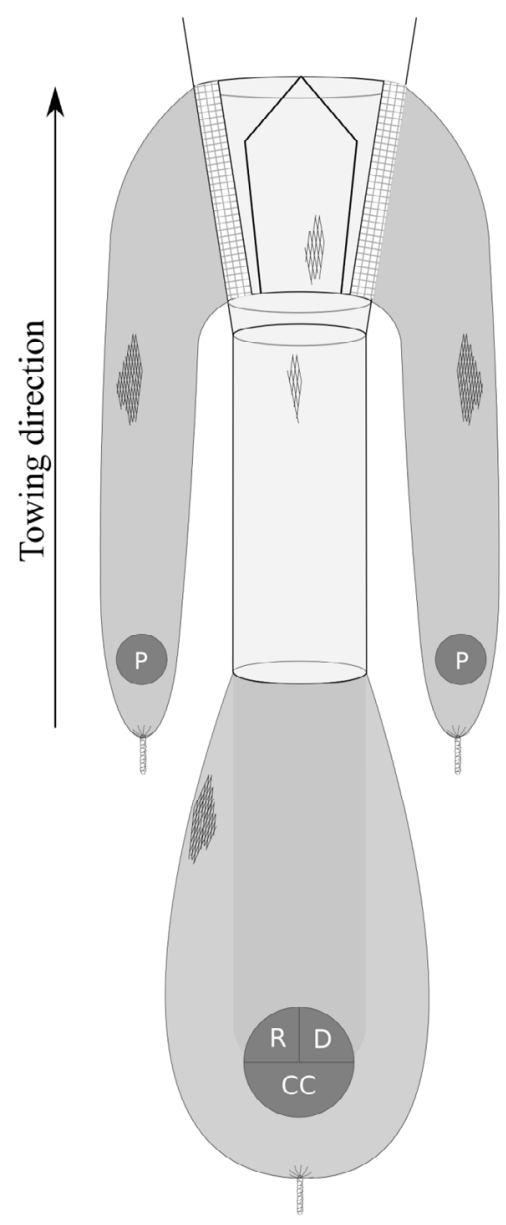

Fig. 3. Compartment-wise experimental design applied to the data collection. P represents the side panel compartments; the codend compartment is a combination of three different subcompartments: codend landed catch (R), codend discarded catch (D), and cover codend catches (CC).

\subsection{Data analysis}

\subsubsection{Modelling release efficiency of the SLEP}

We define the release efficiency of the SLEP as the probability for a fish to escape through one of the SMPs. Mathematically this is described with the following structural model:

$$
e_{\mathrm{SLEP}}(l, v)=C \times\left(1-r_{c}(l, L 50, S R)\right) .
$$

This model (Eq. (1)) quantifies the length-dependent probability for a fish to be released through the SMPs, where $\boldsymbol{v}=(C, L 50, S R)$. Model (1) is similar in structure to the model used by Zuur et al. (2001) to describe the escape probability for haddock and whiting through a SMP inserted into the top section of the extension piece. The functional structure of model (1) accounts for the fact that not all fish necessarily come into contact with the SMPs. As a consequence, the probability that a fish will make contact with the SLEP is modelled by a length-independent number $C$, which was constrained to the interval $[0.0,1.0]$. A value of $C=1.0$ estimates that all fish entering the SLEP zone will make contact with the selective device, while if, for example, $C=0.5$, then the probability of contact falls to $50 \%$. Once a fish makes contact with the SLEP, the probability that it will escape depends on whether or not it can pass through the open mesh, being the later part of the condition modelled by the function $r_{c}(l, L 50, S R)$. This function quantifies the probability that fish with length $l$ are retained by the escape panels, on the condition that fish make contact with the panel. The parameter $L 50$ represents the fish length with $50 \%$ probability of retention by SLEP, and $S R$ is the length range between lengths with $75 \%$ and $25 \%$ probability of retention. Three different functions, logit (Eq. (2)), probit (Eq. (3)), and Gompertz (Eq. (4)), often used for modelling codend size selectivity (Wileman et al. 1996), were considered here as potential candidates to describe $r_{c}(l, L 50, S R)$ :

$$
\begin{aligned}
r_{c}(l, L 50, S R) & =\frac{\exp \left(\frac{\ln (9) \times(l-L 50)}{S R}\right)}{1+\exp \left(\frac{\ln (9) \times(l-L 50)}{S R}\right)} \\
r_{c}(l, L 50, S R) & \approx \Phi\left(1.349 \times \frac{(l-L 50)}{S R}\right) \\
r_{c}(l, L 50, S R) & \approx \exp \left(-\exp \left(1.573 \times \frac{(l-L 50)}{S R}-0.366\right)\right) .
\end{aligned}
$$

The logit function (Eq. (2)) is the most applied in selectivity studies, and usually provides curves with slightly flatter tails than the probit function (Eq. (3)), where $\Phi$ is the cumulative distribution function (CDF) of a standard normal distribution (Wileman et al. 1996). The Gompertz function (Eq. (4)) provides asymmetric curves, in contrast to the symmetric curves estimated by equations (2) and (3).

Information on the number of fish measured in the different compartments $\left(P_{i l}, R_{i l}, D_{i l}, C C_{i l}\right)$ and the corresponding subsampling ratios $\left(q P_{i}, q R_{i}, q D_{i}, q C C_{i}\right)$ was collected separately for each haul. For each of the models, we searched for the parameters which make the observed experimental data most likely. Therefore, we minimized the following function:

$$
\begin{array}{r}
-\sum_{l} \sum_{i}^{\text {haul }}\left\{\frac{P_{i l}}{q P_{i}} \times \ln \left(e_{S L E P}(l, v)\right)\right. \\
+\left(\frac{R_{i l}}{q R_{i}}+\frac{D_{i l}}{q D_{i}}+\frac{C C_{i l}}{q C C_{i}}\right) \\
\left.\times \ln \left(1-e_{S L E P}(l, v)\right)\right\},
\end{array}
$$

where $i$ denotes summation over hauls, $l$ denotes summation over length classes.

The choice of a single model among the three candidate models was based on the AIC value (Akaike 1974). Therefore the model resulting in the lowest AIC value was chosen to describe the size selection by SLEP for a given species. Evaluation of the ability of the selected model to describe the data sufficiently well was done following the recommendations stated in Wileman et al. (1996). The first diagnosis was done by calculating the $p$-value on the Pearson's Chi-squared statistic. The $p$-value expresses the likelihood for obtaining, by coincidence, at least as large a discrepancy between the fitted model and the observed experimental data. This $p$-value is based on testing the null hypothesis, that the modelled length-dependent 
release efficiency and the observed experimental data belong to the same length-dependent distribution. Therefore, this $p$ value should not be $<0.05$ for the fitted model to be a candidate to model the size-selection data. To calculate this fit statistics, data were pooled without raising them, to avoid making them appear artificially stronger than they are. If the model selected did not produce an acceptable $p$-value, it had to be determined whether the failure was caused by the model's inability to describe the length-based structure of the data, or simply caused by overdispersion in the data. We plotted the modelled curve against the experimental rates to check for patterns in the deviations between model and data (Wileman et al. 1996; Madsen et al. 2012). In case of no clear pattern, we would assume that poor fit statistics would be due to overdispersion in data.

\subsubsection{Indicators for SLEP release efficiency}

Three indicators were calculated for each species, to help evaluate the SLEP's effectiveness at releasing fish from the gear. Contrary to the size-selection properties, which provide information independent of the size structure of the fished population, the indicators defined in this section depend directly on the size structure of the population. Thus, these indicators supplement the evaluation of size-selective properties with properties that depend directly on a population size structure in the specific fishery. The following indicators were used:

$$
n P=\frac{\sum_{l} \sum_{i}^{\text {haul }} \frac{P_{i l}}{q P_{i}}}{\sum_{l} \sum_{i}^{\text {haul }}\left(\frac{P_{i l}}{q P_{i}}+\frac{R_{i l}}{q R_{i}}+\frac{D_{i l}}{q D_{i}}+\frac{C C_{i l}}{q C C_{i}}\right)} .
$$

$n P$ is the proportion of fish over the full range of length classes released by the SLEP. In addition we evaluated such proportions for the catch fractions below and above minimum landing size (MLS). Therefore $n P_{-}$and $n P_{+}$represent the proportion of fish below and above MLS that escaped through the SLEP. The indicators $n P_{-}$and $n P_{+}$were only applied to species with MLS (hake, MLS $=27 \mathrm{~cm}$, total length; megrim $=20 \mathrm{~cm}$, total length; Norway lobster $=2 \mathrm{~cm}$, cephalothorax length $(\mathrm{EC}$ 850/98))

\subsubsection{Assessment of confidence intervals}

The $95 \%$ confidence intervals (CIs) for the averaged escape curve $e_{S L E P}(l, v)$ (model 1), and for model parameters $\boldsymbol{v}=(C, L 50, S R)$, were estimated using double bootstrapping, based on the technique introduced in selectivity studies by Millar (1993). The double bootstrap technique takes into account both the within-haul and between-haul variation in the release efficiency of the SLEP. To account for the betweenhaul variation, the experimental hauls were resampled with replacement at each bootstrap iteration until the same number of hauls as the original dataset was reached. Within each resampled haul, the data for each length class was resampled with replacement to account for the within-haul variation. The inner resampling of the data in each length class was performed prior to the raising of the data, to avoid underestimation of the within-haul variation. Each bootstrap iteration resulted in a "pooled" set of data, which was then analyzed according to equation (1), resulting in an individual $e_{S L E P}(l, v)$ curve. This procedure was repeated a total of 2000 times, and the simulated population of results were used to calculate the "Efron percentile" 95\% confidence limits (Efron 1982; Chernick 2007) for the $e_{S L E P}(l, v)$ curve and the selective parameters $\boldsymbol{v}=(C, L 50, S R)$. This approach, which avoided underestimating CIs when averaging over hauls, is identical to the one described in Sistiaga et al. (2010), Eigaard et al. (2012), and Herrmann et al. (2012). The CIs for $n P_{-}, n P_{+}$, and $n P$ were also assessed by including these parameter estimates in the same bootstrap scheme used for $e_{S L E P}(l, v)$.

The size selectivity analyses were performed using the software tool SELNET. Additional information about the software can be found in Sistiaga et al. (2010), Frandsen et al. (2011), Wienbeck et al. (2011), and Herrmann et al. (2012).

\section{Results}

Between 21 and 25 May 2012, 13 valid hauls were performed using the test gear, in the same area where the vessel operates during commercial fishing (Fig. 2). All hauls were conducted during daylight hours and in good weather conditions (1-3 Beaufort scale). Fishing depth ranged from $142 \mathrm{~m}$ to $421 \mathrm{~m}$ (average depth $303 \mathrm{~m}$ ), while fishing duration varied between 2 and $5 \mathrm{~h}$ (Table 1). Megrim was the species taken most frequently during the sea trials and was observed in all experimental hauls. In all, 1930 megrim individuals were length measured over hauls. Hake was observed in 12 hauls (1276 individuals measured), while Norway lobster and catshark were only observed in 9 hauls (744 and 554 individuals measured, respectively; Table 1).

\subsection{Modelling release efficiency of the SLEP}

The Gompertz model was identified as the best model (AIC) for describing hake and Norway lobster data, while probit was chosen for megrim data. All candidate models yielded the same AIC value for the catshark; therefore, the logit model was selected for this species analysis, because it is the most common model used in selectivity studies (Table 2 ).

All models selected to describe the experimental data had poor fit statistics, with $p$-values $<0.001$ (Table 3 ). A visual inspection of Figure 4 indicated that all models provided reasonably good descriptions of the structure of the experimental data, except for hake above $30 \mathrm{~cm}$, where the data of a few length classes do not follow the main trend of the curve. This problem is caused by the low catches obtained for hake above $30 \mathrm{~cm}$ (Fig. 4), which is well reflected by the wide CI provided by the double bootstrapping method. It was therefore assumed that the low $p$-values obtained for megrim, Norway lobster and catshark were caused by overdispersion in the experimental data. Based on this, we were confident in applying the selected models to describe the release efficiency of the SLEP for each species investigated, with the exception of hake above $30 \mathrm{~cm}$. The contact probability estimated by the SLEP release-efficiency model for hake obtained the highest value of all species studied ( $C=0.62(0.45-1.00)$; Table 3$)$. Considering the $\mathrm{CI}$ associated with the hake contact probability, it is likely that at least $45 \%$ of all hake entering the SLEP zone 


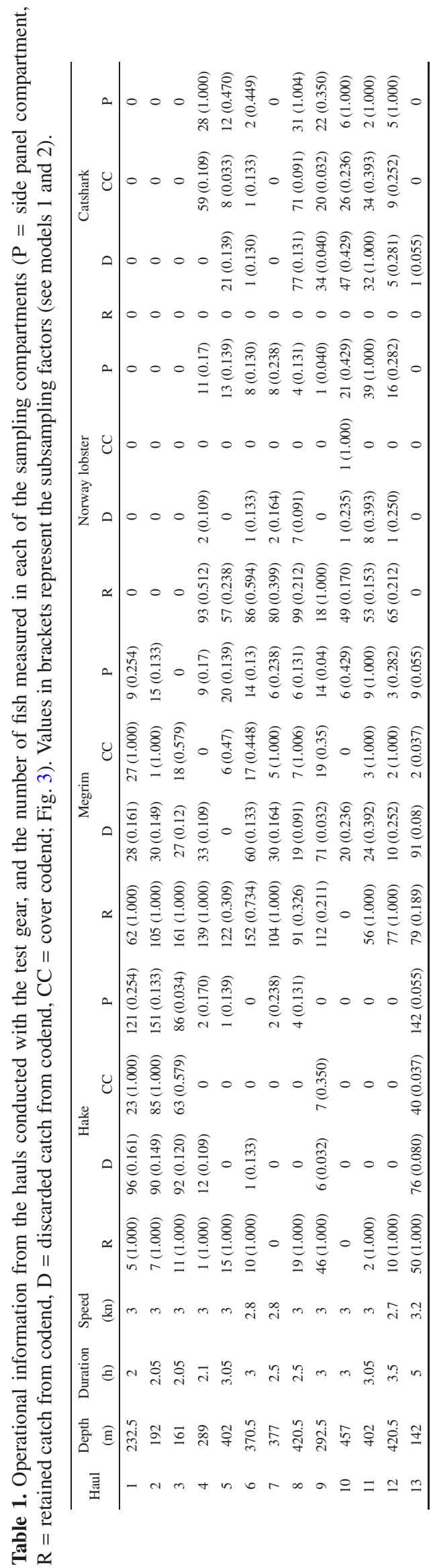

Table 2. Calculated AIC value for the candidate models for describing SLEP release efficiency. Selected models' values in bold.

\begin{tabular}{ccccc}
\hline Model & Hake & Megrim & Norway lobster & Catshark \\
\hline Logit & 15403.09 & 6121.35 & 2358.91 & $\mathbf{5 8 0 0 . 3 8}$ \\
Probit & 15401.87 & $\mathbf{6 1 1 8 . 2 5}$ & 2361.16 & 5800.38 \\
Gompertz & $\mathbf{1 5 3 9 4 . 7 2}$ & 6125.64 & $\mathbf{2 3 5 7 . 5 9}$ & 5800.38 \\
\hline
\end{tabular}

attempted to escape through the SMPs. The species with the second highest contact probability was Norway lobster $(C=$ $0.51(0.14-1.00))$, but the wide CI associated with the expected value reduced the inferential power of the estimate. The lowest contact probabilities were found for megrim and catshark, with average values below $50 \%(C=0.44(0.14-1.00)$ and $C=0.41(0.18-0.53)$, respectively).

The size selectivity for the hake making contact with the SLEP yielded an $L 50=33.87 \mathrm{~cm}(14.88-46.17 \mathrm{~cm})$, a value $\sim 7 \mathrm{~cm}$ above the MLS. This $L 50$ value and the reduced proportion of fish with lengths above MLS observed in the catches, explains why most hake were observed in the side covers (Fig. 4). On the other hand, the large selection range $(S R=$ $18.98 \mathrm{~cm}(0.10-48.10 \mathrm{~cm}))$ explains the slow decrease in release efficiency with increasing fish length (Fig. 4). The average contact $L 50$ estimated for megrim was below species MLS $(L 50=15.47 \mathrm{~cm}(6.63-21.23 \mathrm{~cm}))$, while the selection range was less than half of the value estimated for hake $(S R=7.26 \mathrm{~cm}(1.02-13.52 \mathrm{~cm}))$, providing a sharper escaping curve for the flatfish. The estimated $L 50$ for Norway lobster was above the species MLS $(L 50=3.20 \mathrm{~cm}(0.10-5.16 \mathrm{~cm}))$, which could result in considerable economic loss if this species were a primary target species of the fishery. Contrary to the other species, the length-dependent catch proportions of catshark in the lateral covers do not show a clear size selection signature. This lack of trend results in a very low estimation of the selection range value $(S R=0.10(0.01-1.82))$, which explains the knife-edge shape of the estimated curve (Fig. 4). Finally, the length of $50 \%$ retention for catshark is estimated with high uncertainty $(L 50=28.35 \mathrm{~cm}(23.23-63.71 \mathrm{~cm}))$

\subsection{Indicators for SLEP release efficiency}

The population-dependent indicators estimate that between $\sim 42 \%$ and $\sim 70 \%$ of the total number of hake entering the gear would escape through SLEP during fishing $n P=59.17 \%$ (41.87-69.31\%; Table 4). The values of the indicator that summarizes average percentage of retained individuals below MLS provided results similar to the previous ones $\left(n P_{-}=59.80 \%(44.01-69.82 \%)\right)$, while the expected marketable catch losses were estimated at $24.14 \%$, $\left(n P_{+}=24.14 \%(5.38-50.57 \%)\right)$. The adoption of the SLEP in the fishery would also help reduce the bycatch of undersized megrim $\left(n P_{-}=17.80 \%(10.98-28.37 \%)\right)$, and the marketable catch losses for the flatfish species would be less than $10 \%$ $\left(n P_{+}=8.73 \%(3.23-14.51 \%)\right)$. By using the current mesh size in the SLEP design, the analysis predicts considerable catch losses of marketable Norway lobster $\left(n P_{+}=17.10 \%(11.40\right.$ $24.76 \%)$ ). Only one individual below MLS was observed during the experimental sea trials; therefore, the $n P_{-}$indicator was not calculated for Norway lobster. Finally, the indicator for 

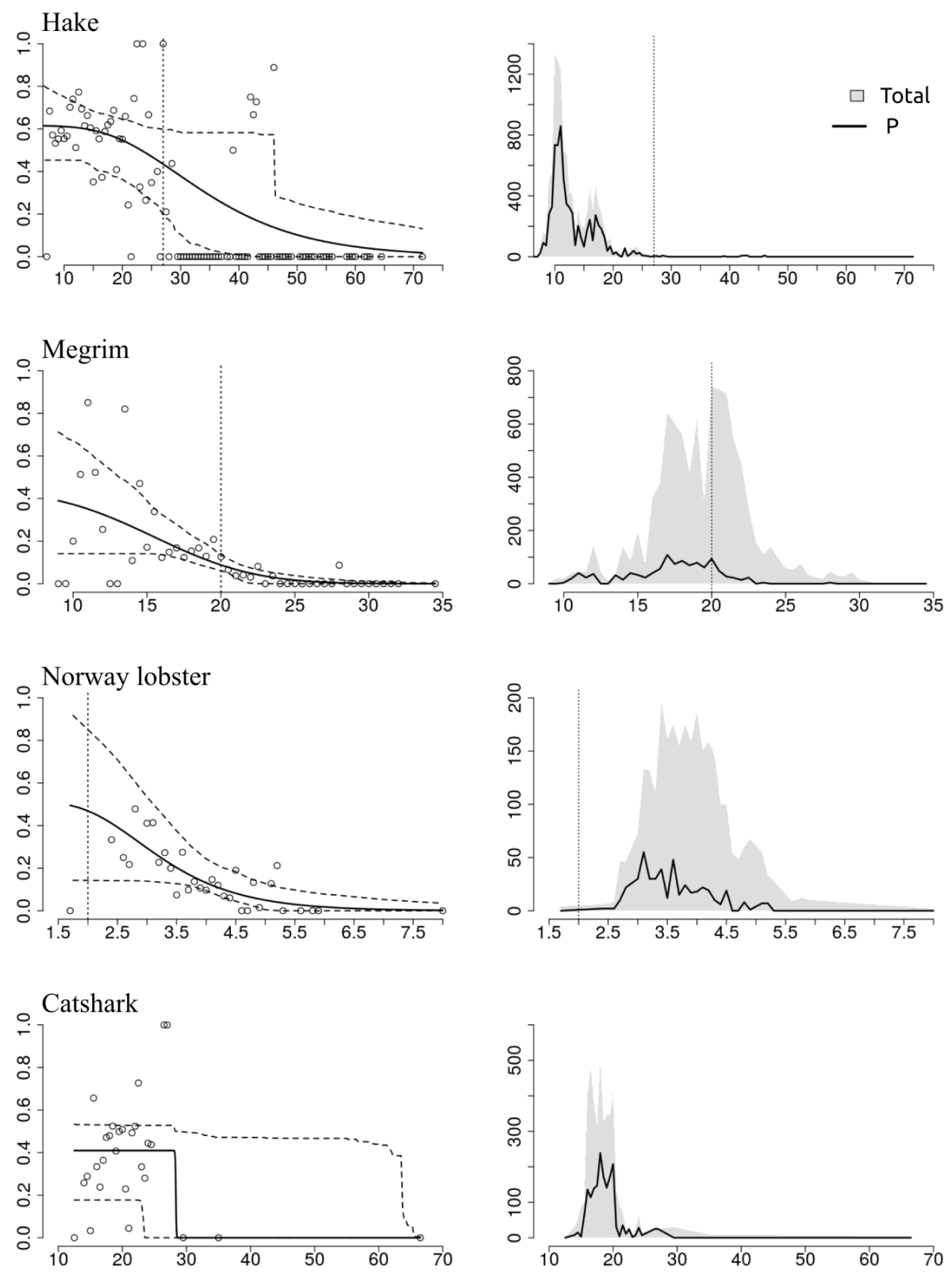

Fig. 4. Left: SLEP release efficiency curves (solid black line) and associated 95\% CI (dashed black line) for the species considered. Vertical dotted lines represent species MLS. Right: raised number of fish in the side panel covers (SP, solid line) compared with the total fish caught. The body length of Norway lobster corresponds to cephalothorax measurements.

Table 3. Parameters estimated by the best SLEP models for the different species analyzed, together with fit statistics. Efron percentile bootstrap $\mathrm{CI}$ in brackets.

\begin{tabular}{ccccc}
\hline Parameter & Hake & Megrim & Norway lobster & Catshark \\
\hline$C$ & $0.62(0.45-1.00)$ & $0.44(0.14-1.00)$ & $0.51(0.14-1.00)$ & $0.41(0.18-0.53)$ \\
L50 $(\mathrm{cm})$ & $33.87(14.88-46.17)$ & $15.47(6.63-21.23)$ & $3.20(0.10-5.16)$ & $28.35(23.23-63.71)$ \\
SR $(\mathrm{cm})$ & $18.98(0.10-48.10)$ & $7.26(1.02-13.52)$ & $1.48(0.10-4.30)$ & $0.10(0.01-1.82)$ \\
Deviance & 181.49 & 105.02 & 50.76 & 87.40 \\
d.o.f. & 103 & 45 & 29 & 25 \\
p-value & $<0.001$ & $<0.001$ & $<0.001$ & $<0.001$ \\
\hline
\end{tabular}


Table 4. Values for the population-dependent indicators for adapting SLEP to the commercial fishery. The values indicate the expected percentage of fish escaping through the lateral side panels once they enter the SLEP zone. Values in brackets represent Efron percentile 95\% CI. Species Minimum Landing Size (MLS) showed in the last row of the table.

\begin{tabular}{ccccc}
\hline Parameter & Hake & Megrim & Norway lobster & Catshark \\
\hline$n P(\%)$ & $59.17(41.87-69.31)$ & $14.50(10.52-19.41)$ & $17.08(11.39-24.71)$ & $40.82(16.13-53.77)$ \\
$n P-(\%)$ & $59.80(44.01-69.82)$ & $17.80(10.98-28.37)$ & NA & NA \\
$n P+(\%)$ & $24.14(5.38-50.57)$ & $8.73(3.23-14.51)$ & $17.10(11.40-24.76)$ & NA \\
$M L S(\mathrm{~cm})$ & 27 & 20 & 2 & NA \\
\hline
\end{tabular}

the catshark data estimated that $\sim 40 \%$ ( $n P=40.82 \%(16.13-$ $53.77 \%)$ ) of the total number entering the trawl would be released by SLEP before they entered the codend.

\section{Discussion}

New concepts for selection devices developed for specific bycatch problems are required, more than ever, in those regions where the problem of discards has been addressed by means of restrictive legislation. This is the case in European fisheries, where a landing obligation for quoted species has been implemented in the new Fisheries Policy reform (EU1380/2013) towards sustainable exploitation of Community Fisheries.

This study assessed the release efficiency of the SLEP, a new selective device based on positioning two long SMPs in the lateral sides of the tapered section of the trawl belly, and supplemented with a pentagon-shaped guiding device to enhance fish contact with the escape windows. The conceptual basis of the SLEP was proposed by fishermen, after being asked to provide advice on new selectivity strategies adapted to the studied fishery. The industry also contributed to development and testing of the new device. Rather than imposing technical solutions developed in other regions, we consider that enhancing collaboration with the local industry to address concrete bycatch problems improves the probability of the proposed solution being adopted in the commercial fishery.

In addition to the size selectivity properties of this prototype, it was of primary interest in this study to quantify the probability that a fish will make contact with the SMP. By estimating such probabilities, we intended to evaluate whether this positioning provides better results than those reported for the commonly applied top panel positioning in other designs.

The new device was found by the crew to be easy to handle during the manoeuvres and to store on the net drum. Since it was not clogged during fishing, it did not require special maintenance efforts. In general, large catches were found in the side covers during the sea trials, confirming that many fish made contact with the SLEP and escaped through it. The models used to describe the experimental data (models 1 and 2) successfully quantified the probability of escape attempts (contact probability) by species, and the size selection properties of the new device. The asymmetric Gompertz curve was selected to describe the size selection of hake and Norway lobster. The large differences in the AIC value between candidate models applied to hake data (Table 2) demonstrate that the Gompertz curve clearly improved the model fit compared to the symmetric logit and probit curves, while such improvement is not clear in the case of Norway lobster. The asymmetry in the selection curve estimated for hake is reflected by the slower progression of the right tail (larger sizes) compared to the left tail (smaller sizes) (Fig. 4). This asymmetry in the tails suggests that, in addition to the physical relation between body length and escapement probability, other length-dependent effects might influence the use of the open meshes to escape. We could speculate that larger fish might have a lower probability of making contact with the SLEP than smaller fish. This length-dependent contact probability might explain the asymmetry of the estimated curve. The hake model estimated that $62 \%$ of the individuals entering the SLEP zone attempted to escape through the side panels $(C=0.62)$. Although not directly comparable, this value clearly improves the $\sim 4 \%$ contact probability estimated for the SMP tested in the Basque Norway lobster fishery operating in the Bay of Biscay, which was mounted on the top of the net, without any guiding panel complementing the selective device (Alzorriz et al. 2016). Underwater video recordings collected by Alzorriz et al. (2016) showed hake to simply drift towards the codend when passing through the section where the SMP was mounted, without displaying any attempts to use the top window to escape. As a result, implementing a simple SMP mounted on the top of the net might not be an effective strategy, if the objective is to improve the escape possibilities for hake, as in the case of the French demersal fishery operating in the Bay of Biscay (Nikolic et al. 2015). The higher contact probability obtained for hake in the present study supports the selection concept presented here, which relies on positioning SMPs in the natural path of the fish in the gear. We assume that the insertion of the pentagon-shaped guiding panel helped raise the probability that hake would make contact with the SLEP on their way to the codend.

The $L 50$ for hake was estimated to be $33.87 \mathrm{~cm}(14.88$ $46.17 \mathrm{~cm}$ ), a value unexpectedly low considering the potential size selection properties of square meshes with similar sizes. For example, fall-through experiments (Herrmann et al. 2009) conducted in Alzorriz et al. (2016), estimated for hake a potential $L 50$ value of $51.05 \mathrm{~cm}$ when using $100 \mathrm{~mm}$ square mesh. This large difference between the experimental and the theoretical estimate might be related to the way in which the fish made contact with the mesh. In the mentioned fall-through experiment, it was assumed that fish would make contact with the mesh with an optimal body orientation. Contrary to this, we argue that fish making contact with the SLEP did so in a range of different body orientations, explaining the small $L 50$ value and the large SR estimated for hake. Further, it is not clear to what extend the forces acting during towing altered the square geometry of SLEP meshes. We speculate that 
the longitudinal towing forces might produce a reduction in mesh openness, thereby reducing the potential selectivity of the panel. Additional sea trials including underwater video observations and specific experimental designs would help to assess the mechanical behaviour of the SLEP during towing, and to understand how the different fish species interact with the guiding panel and the escape panels under different physical conditions (i.e. light conditions or fishing depth). Such information would be required to better understand the quantitative results presented here.

Alzorriz et al. (2016) estimated that $47 \%$ of undersized hake escaped through the $70 \mathrm{~mm}$ codend tested, while only $4 \%$ escaped through the SMP mounted on top. Since the codend used in Alzorriz et al. (2016) is similar to the commercial codends used in the present study, we argue that supplementing the selectivity of the standard codend with the SLEP would drastically reduce the bycatch of undersized hake in the commercial catches.

The analysis estimated that fewer than half of the megrim individuals entering the SLEP zone attempted to escape through it $(C=0.44)$, and the selective properties of the SMPs reduced the marketable losses to less than 10\% (Table 4).

The model estimated that half of the Norway lobsters entering the SLEP zone made contact with the side panels, and the species' $L 50$ was $1.2 \mathrm{~cm}$ above the species' MLS. As a result, $\sim 17 \%$ marketable losses can be expected, using the current SLEP configuration. These potential catch losses are not admissible in commercial fisheries where Norway lobster is the primary target. Assuming that this species rolls over the lower sheet of the trawl towards the codend (Main and Sangster 1985), we believe that reducing the mesh size in the first lower rows of the side panels might reduce the losses of the marketable fraction observed with the setup presented here.

This study demonstrates that mounting long, square-mesh panels in the lateral sides of the belly section, combined with a pentagonal-shaped guiding panel, can significantly improve the release efficiency observed in standard SMPs on passive fish species such as hake. The landing obligation implemented in fisheries from 2016 onwards may be the required incentive to boost the search for technological solutions. In such a case, we consider the SLEP concept as a promising solution to be adopted by the industry in order to reduce the large amounts of juvenile hake bycatch occurring in the fishery. Based on these promising results obtained for the studied fishery, the SLEP might also be a potential tool for improving species and size selection in other trawl fisheries where the traditional use of SMPs is not effective.

Acknowledgements. We thank the crew of the FV "Nuevo San Cibrán" for their valuable help during on-board sampling. We also express our gratitude to the Tecnopesca PyM staff for their intensive work in producing and repairing the gear used in this paper, to ARVI staff for project management, and to Annemarie Schütz for helping to illustrate this paper (Figs. 1 and 3). This study was carried out as part of the project "Desarrollo y experimentación encampaña de un arte selectivo para la pesquería de arrastre de litoral Cantábrico Noroeste" (Ministerio de Medio Ambiente y Medio Rural y Marino).

\section{References}

Alzorriz N., Arregi L., Herrmann B., Sistiaga M., Casey J., Poos J.J., 2016, Questioning the effectiveness of technical measures implemented by the Basque bottom otter trawl fleet: implications under the EU landing obligation. Fish. Res. 175, 116-126.

Akaike H., 1974, A new look at the statistical model identification. IEEE Trans. Auto. Control 19, 716-723.

Arkley K., 1990, Fishing trials to evaluate the use of square mesh selector panels fitted to Nephrops trawls - MFV Heather Sprig (BCK 181) November/December 1990. Seafish Report SR383.

Armstrong M.J., Briggs R.P., Rihan D., 1998, A study of optimum positioning of square-mesh escape panels in Irish Sea Nephrops trawls. Fish. Res. 34, 179-189.

Bellido J.M., Santos M.B., Pennino M.G., Valeiras X., Pierce G.J., 2011. Fishery discards and bycatch: solutions for an ecosystem approach to fisheries management? Hydrobiologia, 670, $317-$ 333.

Briggs R., 1992, An assessment of nets with a square mesh panel as a whiting conservation tool in the Irish Sea Nephrops fishery. Fish. Res. 13, 133-152.

Catchpole T., Revill A., 2008, Gear technology in Nephrops trawl fisheries. Rev. Fish Biol. Fish. 18, 17-31.

Catchpole T., Frid C., Gray T., 2005, Discards in North Sea fisheries: causes, consequences and solutions. Mar. Policy 29, 421-430.

Chernick M., 2007, Bootstrap methods: a guide for researchers and practitioners. Wiley, New York.

Diamond B., Beukers-Stewart B.D., 2011, Fisheries discards in the North Sea: waste of resources or a necessary evil? Rev. Fish. Sci. 19, 231-245.

EC, 1998, Council Regulacion No. 850/98 of 30 March 1998 for the conservation of fishery resources through technical measures for the protection of juveniles of marine organisms. Official Journal of the EU L, 125, 1-36.

Efron B., 1982, The jackknife, the bootstrap and other resampling plans. SIAM Monograph No. 38, CBMS-NSF.

EU, 2013, Regulation No. 1380/2013 of The European Parliament And Of The Council of 11 December 2013, On The Common Fisheries Policy, Official Journal of the European Union L $354 / 22$.

Fernandes A.C., Pérez N., Prista N., Santos J., Azevedo M., 2015, Discards composition from Iberian trawl fleets. Mar. Policy 53, 33-44.

Frandsen R.P., Holst R., Madsen N., 2009, Evaluation of three levels of selective devices relevant to management of the Danish Kattegat-Skagerrak Nephrops fishery. Fish. Res. 97, 243-252.

Frandsen R., Herrmann B., Madsen N., Krag L.A., 2011, Development of a codend concept to improve size selectivity of Nephrops (Nephrops norvegicus) in a multi-species fishery. Fish. Res. 111, 116-126.

Glass C.W., 2000, Conservation of fish stocks through bycatch reduction: a review. North East. Nat.7, 15.

Graham N., Kynoch R.J., 2001, Square mesh panels in demersal trawls: some data on haddock selectivity in relation to mesh size and position. Fish. Res. 49, 207-218.

Graham N., O’Neill F.G., Fryer R.J., Galbraith R.D., Myklebust A., 2004, Selectivity of a $120 \mathrm{~mm}$ diamond cod-end and the effect of inserting a rigid grid or a square mesh panel. Fish. Res. 67, $151-161$.

Greenstreet S.P., Spence F.E., McMillan J.A., 1999, Fishing effects in northeast Atlantic shelf seas: patterns in fishing effort, diversity and community structure. V. Changes in structure of the North Sea groundfish species assemblage between 1925 and 1996. Fish. Res. 40, 153-183. 
Hall M.A., Alverson D.L., Metuzals K.I., 2000, By-catch: problems and solutions. Mar. Pollut. Bull. 41, 204-219.

Herrmann B., Krag L.A., Frandsen R.R., Madsen N., Lundgren B., Staehr K.J., 2009. Prediction of selectivity from morphological conditions: methodology and a case study on cod (Gadus morhua). Fish. Res. 97, 59-71.

Herrmann B., Sistiaga M.B., Nielsen K.N., Larsen R.B., 2012, Understanding the size selectivity of redfish (Sebastes spp.) in North Atlantic trawl codends. J. Northw. Atl. Fish. Sci 44, 1-13.

Herrmann B., Wienbeck H., Karlsen J.D., Stepputtis D., Dahm E., Moderhak W., 2015, Understanding the release efficiency of Atlantic cod (Gadus morhua) from trawls with a square mesh panel: effects of panel area, panel position, and stimulation of escape response. ICES J. Mar. Sci. 72, 686-696.

ICES, 2015, Report of the Working Group for the Bay of Biscay and the Iberian waters Ecoregion (WGBIE), 4-10 May 2015, ICES HQ, Copenhagen, Denmark. ICES CM/ACOM:11. 503 pp.

ICES, 2004, The Nephrops Fisheries of the Northeast Atlantic and Mediterranean - A Review and assessment of fishing gear design. ICES Coop. Res. Rep. No. 270.

ICES, 2003, Report of the ICES-FAO working group on fishing technology and fish behaviour. Fisheries Technology Committee, Bergen, Norway, 27-28 June 2003. ICES CM2003/B:07.

Kelleher K., 2005, Discards in the world's marine fisheries. An update. FAO Fish. Tech. Pap. 470.

Madsen N., Herrmann B., Frandsen R.P., Krag L.A., 2012, Comparing selectivity of a standard and turned mesh T90 codend during towing and haul-back. Aquat. Living Resour. 25, 231-240.

Madsen N., 2007, Selectivity of fishing gears used in the Baltic Sea cod fishery. Rev. Fish Biol. Fisher. 17, 517-544.

Main J., Sangster G.I., 1985, The behaviour of the Norway Lobster, Nephrops norvegicus (L.), during trawling. Department of Agriculture and Fisheries for Scotland, Aberdeen. Scottish Fisheries Research Report, No. 34, 1-23.

Millar R.B., 1993, Incorporation of between-haul variation using bootstrapping and nonparametric estimation of selection curves. Fish. Bull. 91, 564-572.
Nikolic N., Diméet J., Fifas S., Salaün M., Ravard D., Fauconnet L., and Rochet, M.-J., 2015, Efficacy of selective devices in reducing discards in the Nephrops trawl fishery in the Bay of Biscay. ICES J. Mar. Sci. doi: 10.1093/icesjms/fsv036.

O’Neill F.G., Kynoch R.J., Fryer R.J., 2006, Square mesh panels in North Sea demersal trawls: separate estimates of panel and codend selectivity. Fish. Res. 78, 333-341.

Real Decreto 1441/1999, de 10 de septiembre, por el que se regula el ejercicio de la pesca con artes de arrastre de fondo en el caladero nacional del Cantábrico y Noroeste. Ministro de Agricultura P.y.A., ed. BOE 1999.

Revill A.S., Catchpole T.L., Dunlin G., 2007, Recent work to improve the efficacy of square-mesh panels used in a North Sea Nephrops norvegicus directed fishery. Fish. Res. 85, 321-327.

Rochet M.J., Trenkel V.M., 2005, Factors for the variability of discards: assumptions and field evidence. Can. J. Fish. Aquat. Sci., 62, 224-235.

Santos J., Herrmann B., Mieske B., Stepputtis D., Krumme U., Nilsson H., 2015, Reducing flatfish bycatch in roundfish fisheries. Fish. Res., in press, DOI : 10.1016/j .fishres .2015.08.025, ISSN: 0165-7836.

Sistiaga M., Herrmann B., Grimaldo E., Larsen R.B., 2010, Assessment of dual selection in grid based selectivity systems. Fish. Res. 105, 187-199.

Wienbeck H., Herrmann B., Moderhak W., Stepputtis D., 2011, Effect of netting direction and number of meshes around on size selection in the codend for Baltic cod (Gadus morhua). Fish. Res. 109, 80-88.

Wileman D.A., Ferro, R.S.T., Fonteyne R., Millar R.B., 1996, Manual of methods of measuring the selectivity of towed fishing gears. ICES Coop. Res. Rep. No. 215.

Zuur G., Fryer R., Ferro R., Tokai T., 2001, Modelling the size selectivities of a trawl codend and an associated square mesh panel. ICES J. Mar. Sci. 58, 657-671. 